\title{
Study of the metabolic effects of Ramadan fasting on patients with type 2 diabetes. Relation to glycemic control, hypoglycemic events and diabetic complications
}

\section{ABSTRACT}

Background. The aim of this study is to evaluate the metabolic effects of Ramadan fasting on patients with type 2 diabetes, and their relation to glycemic control, risk of hypoglycemia, as well as any possible effects on diabetic complications.

Methods. 300 subjects with type 2 diabetes were assessed to evaluate the metabolic effects of Ramadan fasting regarding glycemic control, risk of hypoglycemia and any possible effects on diabetic complications. The examination included measurement of body mass index (BMI), blood pressure, examination of the foot for sensory loss and peripheral vascular disease (PVD) by assessing the vibration sense and calculating the ankle-brachial index (ABI) respectively. Laboratory tests included fasting plasma glucose (FPG), $\mathrm{HbA}_{1 \mathrm{c}^{\prime}}$ complete lipid profile, serum creatinine, urinary albumin-tocreatinine ratio (UACR) and calculation of eGFR

Results. BMI, blood pressure, FPG, and triglycerides levels were lower in patients after Ramadan compared to their levels before Ramadan, while eGFR was higher after Ramadan than it was before Ramadan. Hypoglycemia was highest in patients treated with insulin

Address for correspondence:

Azza Abd Elkarim Ismail

Unit of Diabetes and Metabolism,

Department of Internal Medicine, Faculty of Medicine,

Alexandria University, Egypt

e-mail:dr_azzak@yahoo.com

Clinical Diabetology 2021, 10; 2: 161-168

DOI: 10.5603/DK.a2020.0004

Received: 04.11.2020

Accepted: 28.12.2020 followed by those treated with oral agents including sulfonylureas as compared to oral agents excluding sulfonylureas ( $p=0.002$ ).

Conclusion. Fasting during Ramadan can affect body weight, blood pressure, glycemic parameters and the frequency of acute glycemic complications in patients with type 2 diabetes. Hypoglycemia was highest in patients treated with insulin followed by those treated with oral agents especially sulfonylureas. (Clin Diabetol 2021; 10; 2: 161-168)

Key words: fasting, type 2 diabetes, glycemic control, risk of hypoglycemia

\section{Introduction}

Ramadan is a holy month in the Islamic calendar during which Muslims all over the world fast between dawn and sunset. During Ramadan, Muslims who are ill or have health conditions that may deteriorate upon fasting, including patients with diabetes, are exempted from fasting [1]. However, fasting during Ramadan is highly regarded as a religious practice, any devoted Muslim patients insist on fasting despite being advised not to it by their healthcare providers. It has been estimated that 40-50 million individuals with diabetes fast during the month of Ramadan [2].

Ramadan fasting entails major changes in dietary patterns and frequency. These changes could potentially induce metabolic alterations in both healthy and diseased people [3, 4]. Despite taking fewer meals, this practice is usually compensated by ingesting large 
amounts of sugary food and drinks that are high in carbohydrates and fats, especially when breaking the fast [5]. The overall calorie consumption of individuals with type 2 diabetes has been reported to increase during Ramadan [6, 7]. Moreover, the doses of anti-diabetic agents are often adjusted at this time to reflect the change in lifestyle during Ramadan. One study showed that, among diabetic patients whose doses of oral hypoglycemic agents were modified during Ramadan, $58 \%$ changed the timings of the administration of their medications [8].

During Ramadan, it has also been reported that physical activities, especially exercising, tend to decrease due to fear of hypoglycemia [9]. Patients with diabetes are usually advised by healthcare providers to avoid excessive physical activity during Ramadan because fasting may increase the risk of hypoglycemia, especially a few hours before the sunset meal. However, some studies reported that appropriate levels of physical activity during fasting did not interfere with tolerance to physical exercise [10]. Furthermore, it has also been postulated that the act of fasting may affect glycemic control, which raises questions about the safety of Ramadan fasting for many patients with diabetes. During Ramadan fasting, the decrease in blood glucose levels triggers compensatory mechanisms in the body of healthy individuals which causes reduction in insulin secretion or breakdown of stored glycogen to prevent hypoglycemia [11]. However, this regulation is compromised in patients with diabetes, due to dysfunction of insulin secretion, insulin sensitivity, or both [12].

Therefore, some kind of controversy might arise here. One epidemiological study reported that the risk of severe hypoglycemia increased seven-fold during the month of Ramadan in patients with diabetes [2]. However, another study reported that Ramadan fasting was safe and did not significantly increase the incidence of hypoglycemic events [13].

The aim of this study is to evaluate the metabolic effects of Ramadan fasting on patients with Type 2 diabetes, and their relation to glycemic control, risk of hypoglycemia, as well as any possible effects on diabetic complications.

\section{Subjects}

This prospective study was conducted on 300 subjects with type 2 diabetes, who were recruited from the Diabetes Clinic of the Main University Hospital, Alexandria University, Egypt. Eligible patients were screened and approached to determine their interest in participating in this study 3-6 weeks before Ramadan and were requested to sign an informed consent. All participating patients were assessed again 3-6 weeks after Ramadan, to evaluate the metabolic effects of Ramadan fasting regarding glycemic control, risk of hypoglycemia, as well as any possible effects on diabetic complications.

Inclusion criteria:

- Muslim patients with type 2 diabetes aged 21 and older who were intending to fast in Ramadan and willing to participate in this study.

Exclusion criteria:

- Patients with type 1 diabetes and patients with endocrine or metabolic diseases other than type 2 diabetes;

- Pregnant and lactating women;

- Patients with a recent history of diabetic ketoacidosis and/or severe hypoglycemia within 3 months prior to enrollment in this study;

- Patients with recent history of corticosteroid therapy within 3 months prior to enrollment in this study;

- Patients who are unable to perform self-monitoring of blood glucose and document hypoglycemic events;

- Patients with advanced renal and/or hepatic diseases.

\section{Methods}

After giving their signed informed consent; all the participants were subjected to the following:

A. Full history taking including patient's age, gender, duration of diabetes, smoking, history of hypertension and/or dyslipidaemia, as well as history of chronic diabetic complications. A detailed drug history was obtained including the type of anti-diabetic medication used, their dosing regimen, and other related drugs.

B. Complete physical examination including body weight and height; for the calculation of body mass index (BMI), measurement of blood pressure, and examination of both feet which included assessment of sensory loss by testing the vibration sense using a $128 \mathrm{MH}$ tuning fork and assessment of peripheral vascular disease (PVD) by calculating the ankle-brachial index ( $A B I)$. Patients with an $A B I$ of less than 0.9 were diagnosed as having PVD [14, 15].

C. Laboratory assessment including fasting plasma glucose, $\mathrm{HbA}_{1 \mathrm{c}}$ [16], total cholesterol, high-density lipoprotein cholesterol (HDL-C), low-density lipoproteincholesterol(LDL-C), serumtriglycerides[17], serum creatinine with calculation of estimated glomerular filtration rate (eGFR) [18] and uurinary albumin-to-creatinine ratio (UACR) [18]. 
Table 1. Comparison between pre and post Ramadan according to body mass index $\left(\mathrm{kg} / \mathrm{m}^{2}\right)$, blood pressure $(\mathrm{mm} \mathrm{Hg})$, $A B I, F B G, H b A_{1 c^{\prime}} L D L, H D L, T G s$, eGFR and UACR

\begin{tabular}{|c|c|c|c|}
\hline & Pre-Ramadan & Post-Ramadan & $\mathbf{P}$ \\
\hline BMI $\left[\mathrm{kg} / \mathrm{m}^{2}\right]$ & $28.59 \pm 3.69$ & $27.96 \pm 3.39$ & $<0.001^{*}$ \\
\hline Systolic blood pressure [mm Hg] & $128.8 \pm 12.04$ & $125.8 \pm 9.98$ & $<0.001^{*}$ \\
\hline Diastolic blood pressure [mm $\mathrm{Hg}]$ & $81.0 \pm 8.26$ & $79.60 \pm 6.0$ & $<0.001^{*}$ \\
\hline$A B I$ & $0.94 \pm 0.15$ & $0.93 \pm 0.15$ & 0.191 \\
\hline $\mathrm{FBG}[\mathrm{mg} / \mathrm{dL}]$ & $147.3 \pm 48.79$ & $139.7 \pm 40.84$ & $<0.001^{*}$ \\
\hline $\mathrm{HbA}_{1 \mathrm{c}}[\%]$ & $8.04 \pm 1.60$ & $7.97 \pm 1.52$ & 0.083 \\
\hline LDL-C [mg/dL] & $107.7 \pm 34.78$ & $106.8 \pm 33.47$ & 0.210 \\
\hline $\mathrm{HDL}-\mathrm{C}[\mathrm{mg} / \mathrm{dL}]$ & $45.77 \pm 7.18$ & $45.51 \pm 5.10$ & 0.272 \\
\hline TGs [mg/dL] & $168.7 \pm 52.08$ & $159.2 \pm 39.08$ & $<0.001^{*}$ \\
\hline eGFR $\left[\mathrm{mL} / \mathrm{min} / 1.73 \mathrm{~m}^{2}\right]$ & $73.48 \pm 19.47$ & $74.87 \pm 19.49$ & $<0.001^{*}$ \\
\hline UACR [mg/gm. Cr] & $228.1 \pm 335.2$ & $227.6 \pm 339.6$ & 0.505 \\
\hline
\end{tabular}

$\mathrm{ABI}$ - ankle-brachial index; BMI — body mass index; FBG — fasting blood glucose; eGFR — estimated glomerular filtration rate; TGs — triglycerides; UACR — urinary albumin creatinine ratio; $\mathrm{P}-\mathrm{p}$ value for comparing between Pre-Ramadan and Post-Ramadan. ${ }^{*}$ Statistically significant at $\mathrm{p} \leq 0.05$

All study patients were subjected to Ramadanrelated patient education regarding hypo- and hyperglycemia symptoms, self-monitoring of blood glucose, anti-diabetic drug dosage and timing alteration, diet, fluid intake during Ramadan and when to break the fast. Adjustments were made to anti-diabetic medication dosage and timing in accordance with the International Diabetes Federation DAR Guidelines [19]. Hypoglycemia was defined as a blood glucose level less than $70 \mathrm{mg} / \mathrm{dl}$ and it was classified as minor or major hypoglycemia. Minor hypoglycemia was defined as an event that could be self-managed by patients irrespective of the severity of the symptoms, while severe hypoglycemia was defined as an event that required the assistance of a third party [20].

All patients were observed during the entire month of Ramadan and a post-Ramadan visit was conducted 3-6 weeks after the end of Ramadan. Information was collected about the number of days of fasting during Ramadan, development of hypoglycemia, its frequency and severity. Physical examination included measurement of body mass index (BMI), blood pressure, examination of the feet for sensory loss, and peripheral vascular disease (PVD) by assessing the vibration sense and calculating the $A B I$ respectively. Laboratory tests were performed including fasting plasma glucose, $\mathrm{HbA}_{1 \mathrm{c}^{\prime}}$ complete lipid profile, UACR and serum creatinine, with calculation of eGFR.

\section{Results}

The study included 132 males and 168 females aged between 34 and 72 years (mean age was 54.23 \pm 8.79 years). 168 patients were treated with oral hypoglycemic drugs, 60 patients were treated with insulin and 72 patients were on combination therapy of oral drugs and insulin.

As presented in Table 1, reassessment showed significant reduction in BMI, FPG, triglycerides, systolic and diastolic blood pressure while there was significant increase in mean eGFR post-Ramadan compared to pre-Ramadan values ( $p<0.001, p<0.001, p<0.001$, $p<0.001, p<0.001$ and $p<0.001$ respectively). No significant difference was observed between the two studied periods regarding $\mathrm{HbA}_{1 c^{\prime}} \mathrm{LDL}-\mathrm{C}, \mathrm{HDL}-\mathrm{C}, \mathrm{UACR}$ and $A B I(p=0.083, p=0.210, p=0.272,0.505$ and 0.191 respectively).

Regarding hypoglycemia, patients on twice daily premixed insulin had the highest rate of minor hypoglycemia compared to patients using basal bolus regimen and patients treated with oral drugs. Patients on twice daily premixed insulin and patients on sulfonylurea monotherapy had the highest rates of severe hypoglycemia compared to patients on basal bolus regimen and patients on other oral drugs as shown in Table 2.

As shown in Table 3, patients treated with premixed insulin had more episodes of minor and severe hypoglycemia compared to patients treated with basal bolus regimen and patients treated with oral-basal combination. Sulfonylurea based oral therapy showed higher rate of minor and severe hypoglycemia compared to DPP-4 inhibitors based oral therapy ( $p<0.001$ and $\mathrm{p}<0.001$ respectively).

Males showed a higher rate of severe hypoglycemia than females. Smoker patients showed a higher rate of severe hypoglycemia than non-smokers. Patients with hypertension and patients with dyslipidemia showed a higher rate of both minor and severe hypoglycemia compared to patients without hypertension and dyslipidemia. 
Table 2. Incidence and rate of minor and severe hypoglycemia

\begin{tabular}{lcc}
\hline & $\begin{array}{c}\text { Rate of minor hypoglycemia } \\
\text { (episodes/pt./month) }\end{array}$ & $\begin{array}{c}\text { Rate of severe hypoglycemia } \\
\text { (episodes/pt./month) }\end{array}$ \\
\hline $\mathrm{Mf}$ & $0.0 \pm 0.0$ & $0.0 \pm 0.0$ \\
$\mathrm{Mf}+\mathrm{DP}$ & $0.20 \pm 0.40$ & $0.0 \pm 0.0$ \\
$\mathrm{Mf}+\mathrm{SU}$ & $2.0 \pm 1.02$ & $1.0 \pm 0.0$ \\
$\mathrm{Mf}+\mathrm{DP}+\mathrm{SU}$ & $2.0 \pm 0.0$ & $0.0 \pm 0.0$ \\
$\mathrm{SU}+\mathrm{DP}$ & $5.0 \pm 0.0$ & $1.0 \pm 0.0$ \\
$\mathrm{SU}$ & $5.0 \pm 0.0$ & $3.0 \pm 0.0$ \\
$\mathrm{Mf}+\mathrm{DP}+$ Basal insulin & $1.50 \pm 1.53$ & $0.0 \pm 0.0$ \\
$\mathrm{Mf}+\mathrm{DP}+\mathrm{SU}+$ Basal insulin & $2.0 \pm 0.0$ & $1.0 \pm 0.0$ \\
Basal bolus & $3.50 \pm 1.53$ & $1.0 \pm 0.0$ \\
Premix & $7.0 \pm 0.0$ & $3.0 \pm 0.0$ \\
\hline
\end{tabular}

DP — DPP-4 inhibitors; Mf - metformin; SU — sulfonylureas

Table 3. Comparison between oral drugs / insulin groups according to of minor and severe hypoglycemia on regimen

\begin{tabular}{|c|c|c|c|c|}
\hline & Minor hypoglycemia & $\mathbf{p}$ & Severe hypoglycemia & $\mathbf{p}$ \\
\hline Premix regimen vs oral-basal regimen & $5.67 \pm 1.91$ vs $1.67 \pm 1.26$ & $<0.001^{*}$ & $3.0 \pm 0.0$ vs $0.33 \pm 0.48$ & $<0.001^{*}$ \\
\hline Premix regimen vs basal bolus regimen & $5.67 \pm 1.91$ vs $3.50 \pm 1.53$ & $<0.001^{*}$ & $3.0 \pm 0.0$ vs $1.0 \pm 0.0$ & $<0.001^{*}$ \\
\hline $\begin{array}{l}\text { DPP4 inhibitors -based oral therapy vs SU-based } \\
\text { oral therapy }\end{array}$ & $0.20 \pm 0.40$ vs $3.0 \pm 1.66$ & $<0.001^{*}$ & $0.0 \pm 0.0$ vs $1.67 \pm 0.96$ & $<0.001^{*}$ \\
\hline
\end{tabular}

*Statistically significant at $\mathrm{p} \leq 0.05$. SU — sulfonylureas; $\mathrm{P}-\mathrm{p}$ value for association between different categories

Age, BMI, systolic blood pressure, diastolic blood pressure, FPG, $\mathrm{HbA}_{1 \mathrm{c}^{\prime}} \mathrm{LDL}-\mathrm{C}$, triglycerides and UACR showed significant positive correlation with the rate of minor hypoglycemia both pre-Ramadan and postRamadan while HDL-C, ABI and eGFR showed significant negative correlation with the rate of minor hypoglycemia both during pre-Ramadan and post-Ramadan.

The rate of severe hypoglycemia had significant positive correlation with age, BMI, diastolic blood pressure and triglycerides while it had significant negative correlation with $\mathrm{ABI}$ during pre-Ramadan and postRamadan. No correlation was found between the rate of severe hypoglycemia and eGFR nor UACR. Moreover, the rate of severe hypoglycemia had significant positive correlation with LDL-C, $\mathrm{HbA}_{1 \mathrm{c}^{\prime}}$ FPG and systolic blood pressure and significant negative correlation with HDL-C only in post-Ramadan interval with no correlation with these parameters in pre-Ramadan interval. Correlations are shown in Table 4.

\section{Discussion}

Ramadan fasting is a religious pillar carried out by Muslims all over the world. During Ramadan, Muslims abstain from eating, drinking, and smoking during daylight hours with Iftar being the main meal taken at sunset, and suhoor is a small meal taken before sunrise [21].
Despite taking fewer meals, the overall caloric consumption of individuals with diabetes has been reported to increase during Ramadan [6]. People with diabetes who fast usually are more prone to fluctuations in their blood glucose values depending upon the type, composition, and quantity of food consumed, regularity in medicine taking, alterations in daily physical activities, or occasional binge-eating after breaking the fast [6]. Epidemiological studies of Muslims with diabetes showed that the majority of patients with diabetes mellitus fasted during Ramadan [10, 19, 22].

The results of the current study showed significant reduction of BMI post-Ramadan compared to preRamadan. In accordance with our study, many studies reported weight loss during Ramadan [23]. The diabetes education and medication adjustment in Ramadan (DEAR) program showed a significant reduction in weight, $\mathrm{BMI}, \mathrm{HbA}_{1 \mathrm{c}^{\prime}}$ LDL-C, triglycerides, and hypoglycemic events [24]. In another study, Sfar et al. [25] observed little change in weight and BMI during Ramadan. Our finding was in contrast to Tiboura et al. [26] who reported that the mean body weight and BMI of the patients showed no change despite the marked changes in food habits.

Regarding blood pressure, both systolic and diastolic blood pressure mean values showed significant 
Table 4. Correlation between rate of minor hypoglycemia and rate of severe hypoglycemia with different parameters

\begin{tabular}{|c|c|c|c|c|}
\hline & \multicolumn{4}{|c|}{ Rate of hypoglycemia } \\
\hline & \multicolumn{2}{|c|}{ Minor } & \multicolumn{2}{|c|}{ Severe } \\
\hline & $r_{s}$ & $\mathbf{P}$ & $r_{s}$ & $\mathbf{p}$ \\
\hline Age [years] & 0.506 & $<0.001^{*}$ & 0.570 & $<0.001^{*}$ \\
\hline \multicolumn{5}{|l|}{ BMI $\left[\mathrm{kg} / \mathrm{m}^{2}\right]$} \\
\hline Pre-Ramadan & 0.378 & $<0.001^{*}$ & 0.501 & $<0.001^{*}$ \\
\hline Post-Ramadan & 0.323 & $<0.001^{*}$ & 0.405 & $<0.001^{*}$ \\
\hline \multicolumn{5}{|c|}{ Systolic blood pressure [mm Hg] } \\
\hline Pre-Ramadan & 0.232 & $0.002^{*}$ & 0.143 & 0.118 \\
\hline Post-Ramadan & 0.350 & $<0.001^{*}$ & 0.253 & $0.005^{*}$ \\
\hline \multicolumn{5}{|c|}{ Diastolic blood pressure [mm Hg] } \\
\hline Pre-Ramadan & 0.537 & $<0.001^{*}$ & 0.326 & $<0.001^{*}$ \\
\hline Post-Ramadan & 0.219 & $0.003^{*}$ & 0.456 & $<0.001^{*}$ \\
\hline \multicolumn{5}{|l|}{ FBG } \\
\hline Pre-Ramadan & 0.265 & $<0.001^{*}$ & 0.071 & 0.441 \\
\hline Post-Ramadan & 0.726 & $<0.001^{*}$ & 0.641 & $<0.001^{*}$ \\
\hline \multicolumn{5}{|l|}{$\mathrm{HbA}_{1 \mathrm{c}}$} \\
\hline Pre-Ramadan & 0.530 & $<0.001^{*}$ & 0.018 & 0.847 \\
\hline Post-Ramadan & 0.538 & $<0.001^{*}$ & 0.356 & $<0.001^{*}$ \\
\hline \multicolumn{5}{|l|}{ LDL } \\
\hline Pre-Ramadan & 0.368 & $<0.001^{*}$ & 0.142 & 0.122 \\
\hline Post-Ramadan & 0.305 & $<0.001^{*}$ & 0.284 & $0.002^{*}$ \\
\hline \multicolumn{5}{|l|}{$\mathrm{HDL}$} \\
\hline Pre-Ramadan & -0.248 & $0.001^{*}$ & -0.143 & 0.120 \\
\hline Post-Ramadan & -0.439 & $<0.001^{*}$ & -0.429 & $<0.001^{*}$ \\
\hline \multicolumn{5}{|l|}{ TGs } \\
\hline Pre-Ramadan & 0.654 & $<0.001^{*}$ & 0.284 & $0.002^{*}$ \\
\hline Post-Ramadan & 0.753 & $<0.001^{*}$ & 0.497 & $<0.001^{*}$ \\
\hline \multicolumn{5}{|l|}{ eGFR } \\
\hline Pre-Ramadan & -0.627 & $<0.001^{*}$ & -0.142 & 0.121 \\
\hline Post-Ramadan & -0.674 & $<0.001^{*}$ & -0.143 & 0.120 \\
\hline \multicolumn{5}{|l|}{ UACR } \\
\hline Pre-Ramadan & 0.616 & $<0.001^{*}$ & 0.071 & 0.441 \\
\hline Post-Ramadan & 0.644 & $<0.001^{*}$ & 0.107 & 0.245 \\
\hline
\end{tabular}

*Statistically significant at $\mathrm{p} \leq 0.05$. BMI — body mass index; FBG — fasting blood glucose; eGFR — estimated glomerular filtration rate; $r_{\mathrm{s}}$ - Spearman coefficient; TGs — triglycerides; UACR — urinary albumin creatinine ratio

reduction after Ramadan compared to pre-Ramadan values. Similar results were reported by Bener et al. [27] explored the impact of Ramadan fasting on different biochemical and lifestyle parameters and demonstrated reduction of systolic and diastolic blood pressure with fasting. In contrast to our findings, Sahin et al. [28] reported that $\mathrm{BMI}$, waist circumference and blood pressure were unchanged in patients who fasted during Ramadan.

In the present study, mean FPG was significantly lower post-Ramadan compared to pre-Ramadan. Regarding $\mathrm{HbA}_{1 \mathrm{c}^{\prime}}$ mean $\mathrm{HbA}_{1 \mathrm{c}}$ was lower post-Ramadan but the difference was non-significant. These findings revealed that fasting lead to significant reduction in blood glucose levels which is consistent with other studies [27-29]. Also, there was significant reduction of mean triglyceride level post-Ramadan but no effect was observed on LDL-C

No significant difference was observed regarding mean UACR between pre-Ramadan and post-Ramadan but mean eGFR level was higher than pre-Ramadan level indicating that fasting does not cause any deterioration of renal functions. A previous meta-analysis including six studies confirmed this conclusion [30]. Another study compared a group of CKD patients who fasted during Ramadan to a control group of CKD patients 
who did not fast and reported similar results [31]. Few studies showed worsening renal functions with Ramadan fasting. An observational trial including 65 participants showed worsening of renal functions with Ramadan fasting in $33 \%$ of patients. Interestingly, this study identified young age as a risk factor for worsening renal function with Ramadan fasting in these patients [32]. This may be related to more physical activity associated with more dehydration in this age group.

Regarding lipid profile, no effect was observed on mean LDL-C or HDL-C but mean triglyceride level showed significant reduction post-Ramadan compared to preRamadan. A previous study reported that Ramadan fasting improved blood lipid profile, blood pressure, blood glucose, BMI, and sleeping problems among patients with T2DM [27]. Another study demonstrated reduction of LDL-C and triglycerides in addition to elevation of HDL-C levels in adult males after Ramadan fasting [33].

The results of the current study showed higher frequency of hypoglycemic episodes among insulin treated patients and patients using sulfonylureas. A previous study showed that $2 \%$ of patients with type 2 diabetes experienced at least one episode of hypoglycemia requiring hospitalization during Ramadan [28]. Another study including 493 diabetic patients reported that about $14.6 \%$ of the patients experienced mild hypoglycemia, 3.2\% had severe hypoglycemia and $11.2 \%$ had severe hyperglycemia during Ramadan [34].

Ba-Essa et al. [35] described rates of hypoglycemia during Ramadan according to type of treatment. Hypoglycemia was highest in patients treated with insulin followed by those treated with oral agents including sulfonylureas as compared to oral agents excluding sulfonylureas.

Smokers showed higher rate of severe hypoglycemia than nonsmokers. The relation of smoking to severe hypoglycemia may be attributed to the effect of smoking on insulin clearance, leading to hyperinsulinemia, increasing the risk of postprandial hypoglycemia, and worsening metabolic control [36]. Moreover, hypertensive patients showed higher rate of severe hypoglycemia compared to normotensive patients. It is highly probable that hypoglycemia-induced hypertension is amplified in patients experiencing frequent and severe hypoglycemia which may increase the risk of a broad spectrum of hypertension-related complications [37].

The rate of hypoglycemia had significant positive correlation with BMI. These results are in contrast to Yun et al. [38], who assessed the association between $\mathrm{BMI}$ and the development of severe hypoglycemia in patients with type 2 diabetes and concluded that BMI and severe hypoglycemia were found to be inversely associated. However, BMI was strongly associated with severe hypoglycemia in the males compared to females which is in agreement with our study.

Regarding blood pressure, there was a statistically significant positive correlation between the rate of hypoglycemia and systolic blood pressure post-Ramadan. Diastolic blood pressure had statistically significant positive correlation between the rate of hypoglycemia (pre-Ramadan and post-Ramadan). Frier et al. [39] stated that the hemodynamic changes associated with hypoglycemia included an increase in heart rate and peripheral systolic blood pressure.

Our results showed that there was significant positive correlation between the rate of hypoglycemia and FPG and $\mathrm{HbA}_{1 \mathrm{c}}$. These results contradicts Tsujino et al. [40] who examined the relationship between the occurrence of hypo-/hyperglycemia and $\mathrm{HbA}_{1 \mathrm{c}}$ values and reported that higher the $\mathrm{HbA}_{1 \mathrm{c}}$ values were significantly associated with shorter time in hypoglycemia ( $<70 \mathrm{mg} / \mathrm{dL}$ ).

Regarding LDL, there was a statistically significant positive correlation between the rate of hypoglycemia and LDL. Li et al. [41], found that increased LDL was associated with mild hypoglycemia, severe hypoglycemia, or both in multivariable analysis.

\section{Conclusion}

Pre-Ramadan education can greatly benefit patients with diabetes in maintaining blood sugar control and preventing weight gain. Ramadan fasting reduced BMI, blood pressure, FBG and TGs compared to pre-Ramadan levels while eGFR was higher than pre-Ramadan. Hypoglycemia was highest in patients treated with insulin followed by those treated with oral agents including sulfonylureas as compared to oral agents excluding sulfonylureas. Smokers, patients with hypertension and dyslipidemia showed higher rate of severe and minor hypoglycemia compared to patients without those risk factors.

\section{Acknowledgement}

This work was supported by Internal Medicine Department (Diabetes Unit), Faculty of Medicine, Alexandria University, Egypt.

\section{Conflict of interest}

The authors declare that there is no conflict of interest.

\section{REFERENCES}

1. Bashir MI, Pathan MdF, Raza SA, et al. Role of oral hypoglycemic agents in the management of type 2 diabetes mellitus during Ramadan. Indian J Endocrinol Metab. 2012; 16(4): 503-507, doi: 10.4103/2230-8210.97994, indexed in Pubmed: 22837904. 
2. Salti I, Bénard E, Detournay B, et al. A population-based study of diabetes and its characteristics during the fasting month of Ramadan in 13 countries: results of the epidemiology of diabetes and Ramadan 1422/2001 (EPIDIAR) study. Diabetes Care. 2004; 27(10): 2306-2311, doi: 10.2337/diacare.27.10.2306, indexed in Pubmed: 15451892.

3. Mans KS. Study the effects of Ramadan fasting on the serum glucose and lipid profile among healthy jordanian students. American Journal of Applied Sciences. 2007; 4(8): 565-569, doi: 10.3844/ajassp.2007.565.569.

4. M'guil M, Ragala MA, El Guessabi L, et al. Is Ramadan fasting safe in type 2 diabetic patients in view of the lack of significant effect of fasting on clinical and biochemical parameters, blood pressure, and glycemic control? Clin Exp Hypertens. 2008; 30(5): 339-357, doi: 10.1080/10641960802272442, indexed in Pubmed: 18633757

5. Benaji B, Mounib N, Roky R, et al. Diabetes and Ramadan: review of the literature. Diabetes Res Clin Pract. 2006; 73(2): 117-125, doi: 10.1016/j.diabres.2005.10.028, indexed in Pubmed: 16647781

6. Vasan SK, Karol R, Mahendri NV, et al. A prospective assessment of dietary patterns in Muslim subjects with type 2 diabetes who undertake fasting during Ramadan. Indian J Endocrinol Metab. 2012; 16(4): 552-557, doi: 10.4103/2230-8210.98009, indexed in Pubmed: 22837915.

7. Khaled BM, Belbraouet S. Effect of Ramadan fasting on anthropometric parameters and food consumption in 276 type 2 diabetic obese women. Int J Diabetes Dev Ctries. 2009; 29(2): 62-68, doi: 10.4103/0973-3930.53122, indexed in Pubmed: 20142870.

8. Pinelli NR, Jaber LA. Practices of Arab American patients with type 2 diabetes mellitus during Ramadan. J Pharm Pract. 2011; 24(2): 211-215, doi: 10.1177/0897190010367432, indexed in Pubmed: 21712216.

9. Ziaee V, Razaei M, Ahmadinejad Z, et al. The changes of metabolic profile and weight during Ramadan fasting. Singapore Med J. 2006; 47(5): 409-414, indexed in Pubmed: 16645692.

10. Al-Arouj M, Assaad-Khalil S, Buse J, et al. Recommendations for management of diabetes during Ramadan: update 2010. Diabetes Care. 2010; 33(8): 1895-1902, doi: 10.2337/dc10-0896, indexed in Pubmed: 20668157.

11. Cryer PE, Davis SN, Shamoon H. Hypoglycemia in diabetes. Diabetes Care. 2003; 26(6): 1902-1912, doi: 10.2337/diacare.26.6.1902, indexed in Pubmed: 12766131

12. Almaatouq MA. Pharmacological approaches to the management of type 2 diabetes in fasting adults during Ramadan. Diabetes Metab Syndr Obes. 2012; 5: 109-119, doi: 10.2147/DMSO. S23261, indexed in Pubmed: 22654520.

13. Bonakdaran SH, Khajeh-Dalouie M. The effects of fasting during Ramadan on glycemic excursions detected by continuous glucose monitoring system (CGMS) in patients with type 2 diabetes. Med J Malaysia. 2011; 66(5): 447-450, indexed in Pubmed: 22390099.

14. Armstrong DG, Lavery LA, Vela SA, et al. Choosing a practical screening instrument to identify patients at risk for diabetic foot ulceration. Arch Intern Med. 1998; 158(3): 289-292, doi: 10.1001/ archinte.158.3.289, indexed in Pubmed: 9472210.

15. Boulton AJM, Armstrong DG, Albert SF, et al. Comprehensive foot examination and risk assessment. A report of the Task Force of the Foot Care Interest Group of the American Diabetes Association, with endorsement by the American Association of Clinical Endocrinologists. Phys Ther. 2008; 88(11): 1436-1443, doi: 10.1093/ ptj/88.11.1436, indexed in Pubmed: 19137633.

16. Cowie CC, Rust KF, Byrd-Holt DD, et al. Prevalence of diabetes and high risk for diabetes using $\mathrm{A} 1 \mathrm{C}$ criteria in the U.S. population in 1988-2006. Diabetes Care. 2010; 33(3): 562-568, doi: 10.2337/ dc09-1524, indexed in Pubmed: 20067953.

17. Shepherd J, Barter P, Carmena R, et al. Effect of lowering LDL cholesterol substantially below currently recommended levels in patients with coronary heart disease and diabetes: the Treating to
New Targets (TNT) study. Diabetes Care. 2006; 29(6): 1220-1226, doi: 10.2337/dc05-2465, indexed in Pubmed: 16731999.

18. Eknoyan G, Lameire N, Eckardt K, et al. KDIGO 2012 clinical practice guideline for the evaluation and management of chronic kidney disease. Kidney Int. 2013; 3(1): 5-14.

19. Hassanein M, Al-Arouj M, Hamdy O, et al. International Diabetes Federation (IDF), in collaboration with the Diabetes and Ramadan (DAR) International Alliance. Diabetes and Ramadan: Practical guidelines. Diabetes Res Clin Pract. 2017; 126: 303-316, doi: 10.1016/j.diabres.2017.03.003, indexed in Pubmed: 28347497.

20. International Hypoglycaemia Study Group. Glucose concentrations of less than $3.0 \mathrm{mmol} / \mathrm{l}(54 \mathrm{mg} / \mathrm{dl})$ should be reported in clinical trials: a joint position statement of the American Diabetes Association and the European Association for the Study of Diabetes. Diabetologia. 2017; 60(1): 3-6.

21. Jaleel MA, Raza SA, Fathima FN, et al. Ramadan and diabetes: As-Saum (The fasting). Indian J Endocrinol Metab. 2011; 15(4): 268-273, doi: 10.4103/2230-8210.85578, indexed in Pubmed: 22028997.

22. Jabbar A, Hassanein M, Beshyah SA, et al. CREED study: Hypoglycaemia during Ramadan in individuals with Type 2 diabetes mellitus from three continents. Diabetes Res Clin Pract. 2017; 132: 19-26, doi: 10.1016/j.diabres.2017.07.014, indexed in Pubmed: 28783529.

23. Khaled M, Belbraouet S. Ramadan fasting diet entailed a lipid metabolic disorder among type 2 diabetic obese women. American Journal of Applied Sciences. 2009; 6(3): 471-477, doi: 10.3844/ajas.2009.471.477.

24. Hassanein M. Ramadan focused diabetes education; a much needed approach. J Pak Med Assoc. 2015; 65(5 Suppl 1): S76-S78, indexed in Pubmed: 26013796.

25. Sfar H, Sellami S, Boukhayatia F, et al. Biochemical, physiological and body composition changes in patients with type 2 diabetes during Ramadan fasting. Ibnosina Journal of Medicine and Biomedical Sciences. 2017; 9(6): 164-168, doi: 10.4103/ijmbs. ijmbs_59_17.

26. Tiboura G, Khaled B, Diaf M, et al. Effect of Ramadan Fasting on Serum Glucose and Lipid Profile Among Algerian Type 2 Diabetes Patients. Romanian Journal of Diabetes Nutrition and Metabolic Diseases. 2015; 22(4): 385-392, doi: 10.1515/rjdnmd-2015-0045.

27. Bener A, A Al-Hamaq AOA, Öztürk $M$, et al. Effect of ramadan fasting on glycemic control and other essential variables in diabetic patients. Ann Afr Med. 2018; 17(4): 196-202, doi: 10.4103/ aam.aam_63_17, indexed in Pubmed: 30588933.

28. Sahin SB, Ayaz T, Ozyurt N, et al. The impact of fasting during Ramadan on the glycemic control of patients with type 2 diabetes mellitus. Exp Clin Endocrinol Diabetes. 2013; 121(9): 531-534, doi: 10.1055/s-0033-1347247, indexed in Pubmed: 23934679.

29. Mushtaq R, Akram A, Mushtaq R, et al. Effect of Ramadan fasting on serum insulin and fasting blood glucose in adult obese and overweight population of karachi, pakistan. FUUAST Journal of Biology. 2018; 8(1): 139-149.

30. Bragazzi NL. Ramadan fasting and chronic kidney disease: does estimated glomerular filtration rate change after and before Ramadan? Insights from a mini meta-analysis. Int J Nephrol Renovasc Dis. 2015; 8: 53-57, doi: 10.2147/JJNRD.S61718, indexed in Pubmed: 26082658.

31. Hassan S, Hassan F, Abbas N, et al. Does Ramadan fasting affect hydration status and kidney function in CKD patients? Ann Nutr Metab. 2018; 72(3): 241-247, doi: 10.1159/000486799, indexed in Pubmed: 29518785.

32. Bakhit AA, Kurdi AM, Wadera JJ, et al. Effects of Ramadan fasting on moderate to severe chronic kidney disease. A prospective observational study. Saudi Med J. 2017; 38(1): 48-52, doi: 10.15537/ smj.2017.1.17566, indexed in Pubmed: 28042630.

33. Pathan M, Patil R. Effect of Ramadan fasting on body weight and lipid profile. Biomedical and Pharmacology Journal. 2015; 3(1): 167-170. 
34. Elmehdawi RR, Mukhtad NA, Allaghi NI, et al. Fasting of Ramadan in peoples with diabetes in Benghazi, Libya: an exploratory study. Libyan J Med. 2010; 5, doi: 10.3402/ljm.v5i0.5036, indexed in Pubmed: 21483582

35. Ba-Essa EM, Hassanein M, Abdulrhman S, et al. Attitude and safety of patients with diabetes observing the Ramadan fast. Diabetes Res Clin Pract. 2019; 152: 177-182, doi: 10.1016/j. diabres.2019.03.031, indexed in Pubmed: 30946851.

36. Bott S, Shafagoj YA, Sawicki PT, et al. Impact of smoking on the metabolic action of subcutaneous regular insulin in type 2 diabetic patients. Horm Metab Res. 2005; 37(7): 445-449, doi: 10.1055/s2005-870237, indexed in Pubmed: 16034718.

37. Feldman-Billard S, Massin P, Meas T, et al. Hypoglycemia-induced blood pressure elevation in patients with diabetes. Arch Intern Med. 2010; 170(9): 829-831, doi: 10.1001/archinternmed.2010.98, indexed in Pubmed: 20458093.
38. Yun JS, Park YM, Han K, et al. Presence of macroalbuminuria predicts severe hypoglycemia in patients with type 2 diabetes: a 10-year follow-up study. Diabetes Care. 2013; 36(5): 1283-1289, doi: 10.2337/dc12-1408, indexed in Pubmed: 23248198.

39. Frier BM, Schernthaner G, Heller SR. Hypoglycemia and cardiovascular risks. Diabetes Care. 2011; 34 Suppl 2: S132-S137, doi: 10.2337/dc11-s220, indexed in Pubmed: 21525444.

40. Tsujino D, Nishimura R, Onda Y, et al. The relationship between $\mathrm{HbA1c}$ values and the occurrence of hypoglycemia as assessed by continuous glucose monitoring in patients with type 1 diabetes. Diabetol Metab Syndr. 2016; 8: 53, doi: 10.1186/s13098-0160167-z, indexed in Pubmed: 27478509.

41. Li Y, Mu Y, Ji Q, et al. Hypoglycaemia, Abnormal Lipids, and Cardiovascular Disease among Chinese with Type 2 Diabetes. Biomed Res Int. 2015; 2015: 862896, doi: 10.1155/2015/862896, indexed in Pubmed: 26504840. 